\title{
The Brazilian contribution to the observation of the transit of Venus
}

\author{
Ronaldo Rogério de Freitas Mourão \\ Museu de Astronomia e Ciências Afins do Rio de Janeiro and Universidade do Vale do Acaraú, \\ Sobral, Ceará, Brazil \\ email: mourao@ronaldomourao.com
}

\begin{abstract}
During the second half of the nineteenth century Brazilian astronomers participated in the observations of transit of Venus. In 1874 a Brazilian astronomer, Francisco Antônio de Almeida was sent by the Imperial Observatory to Nagasaki to use the "photographic revolver" invented by Jules Janssen. In 1882 three missions were sent by the Imperial Observatory (Brazil) to observe the transit in St Thomas (Antilles), Punta Arenas (Chile) and Olinda (Brazil). The value of the solar parallax obtained by the Brazilian Commission, led by Luís Cruls, was 8." 808 , representing at that time one of the most precise values.
\end{abstract}

\section{Introduction}

The passage of planet Venus across the solar disk occurred twice in the 19th century, once in 1874 and again in 1882. During the occasion of the Venus transit on 9 December 1874 in Nagasaki, Japan, a young Brazilian astronomer, Francisco de Almeida participated in the French mission operating the French astronomer Jules Janssen's (1824-1907) astronomical revolver, considered the predecessor of the movie system.

During the transit of 6 December 1882, Brazil participated in the great first international enterprise of basic science, establishing three posts of observation out of Rio de
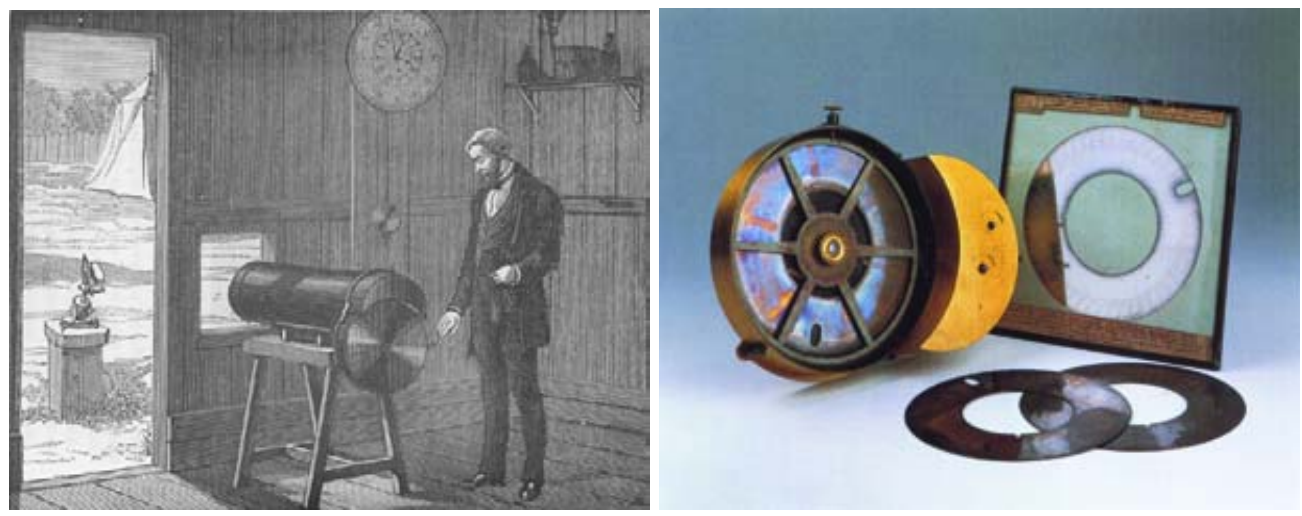

Figure 1. (Left panel) Francisco Antônio de Almeida. The Brazilian astronomer was commissioned and sent by Conde Prados, director of the Imperial Observatory of Rio de Janeiro, to study astronomy in France, when he was invited to participate in the French commission in Nagasaki, where he was responsible for the use of Jules Janssen's photographic revolver (1824-1907). With this device it was possible to obtain very close pictures that were produced on a type of film through which Venus was visualized in front of the Sun. (Right panel) Photographic revolver built by Rédier, used in Nagasaki in 1874. This invention is considered one of the prototype of the today's movies. 

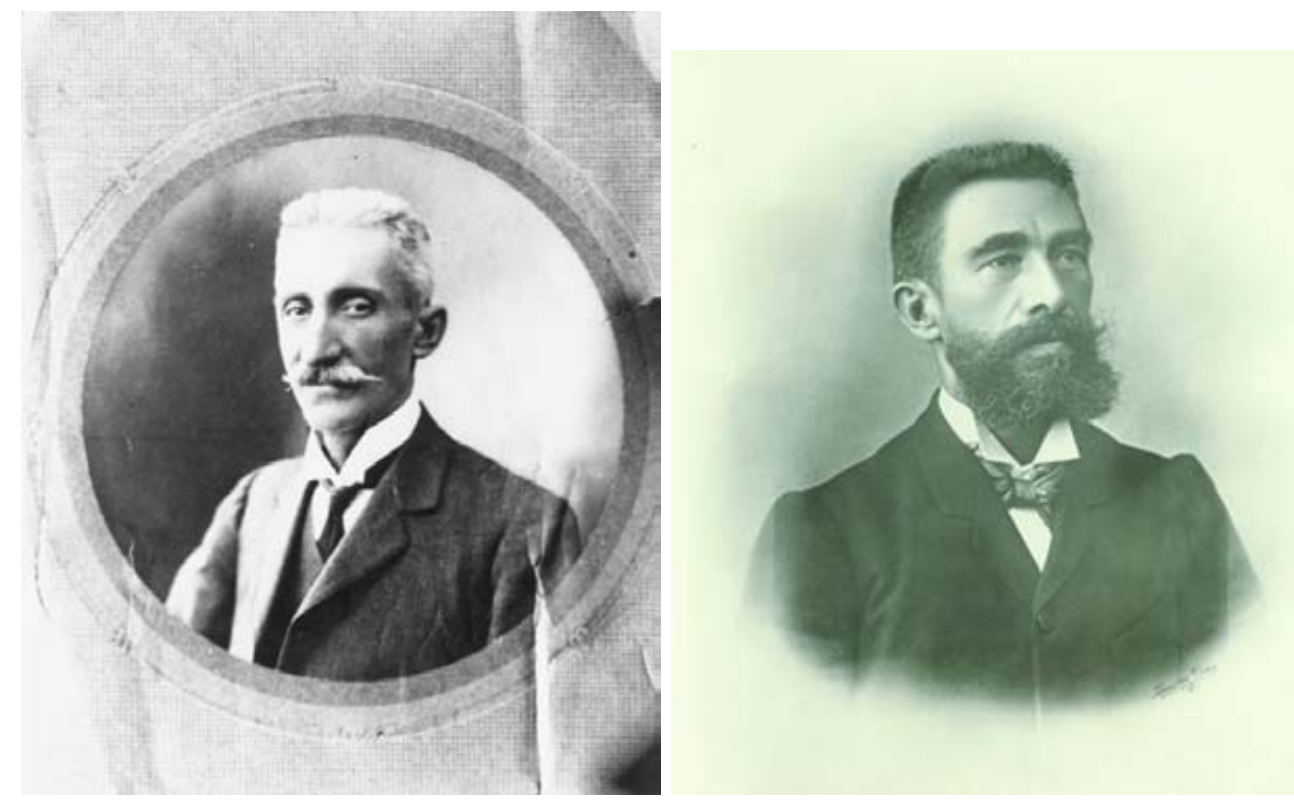

Figure 2. (Left panel) The Brazilian astronomer Julião of Oliveira Lacaille (1851-1926) who graduated in Engineering in France was the responsible for the observations of the passage of Venus by the solar disk in Olinda, 6 December 1882. (Right panel) Luiz Cruls, Chief of the Brazilian Mission, Brazilian astronomer of Belgian origin (1848-1908). Graduating in Engineering at the University of Gand, Cruls remained in the Belgian army up to 1874, when he asked for dismissal and came to Brazil. Invited and commissioned by Emperor Dom Pedro II, he was admitted at the Imperial Observatory under the administration of Emmanuel Liais for whom he substituted. He was the chief of the Brazilian mission that observed the transit of Venus, in Punta Arena, in 1882.

Janeiro: one in Olinda under the leadership of astronomer Julião de Oliveira Lacaille (18511926; Fig. 2 left), and the two others in St Thomas island in the West Indies, and in the city of Punta Arenas in Patagonia, respectively, under the command of hydrograph engineer Antonio Luis von Hoonholtz, a.k.a. Baron of Tefé (1837-1931), and of astronomer Luís Cruls (18481908; Fig. 2 right). In Pernambuco and in the West Indies, in spite of non-favourable weather conditions, there still was some success. The great success, however, was the mission to Patagonia, where Luís Cruls in Punta Arena observed all the phases of the phenomenon. As a result of that, several scientific communications with relative results to astronomy and to natural history accomplished by the Brazilian scientists were presented by Emperor Dom Pedro II to the Academy of Sciences at Paris.

The principal aim of the missions was to determine the distance from Earth to the Sun, one of the most fundamental concerns of astronomy. Besides being a unit of length in the solar system, the distance from Earth to the Sun is the base used to measure the distance to the stars. All the distances measured in the universe depend upon the determination of the ray of the orbit of planet Earth revolving around the Sun. To measure the distance of an object, be it terrestrial or celestial, we have to try to observe them from two different points, separated amongst themselves by a certain distance. The farther away the object to be observed, the greater the separation of the positions of observation needed. Thus, for the objects located within the solar system two distant points of observation from the surface of the Earth should be enough, whilst for a star, away from our solar system, it is necessary to use the diameter of the orbit that Earth describes around the Sun in one year. 


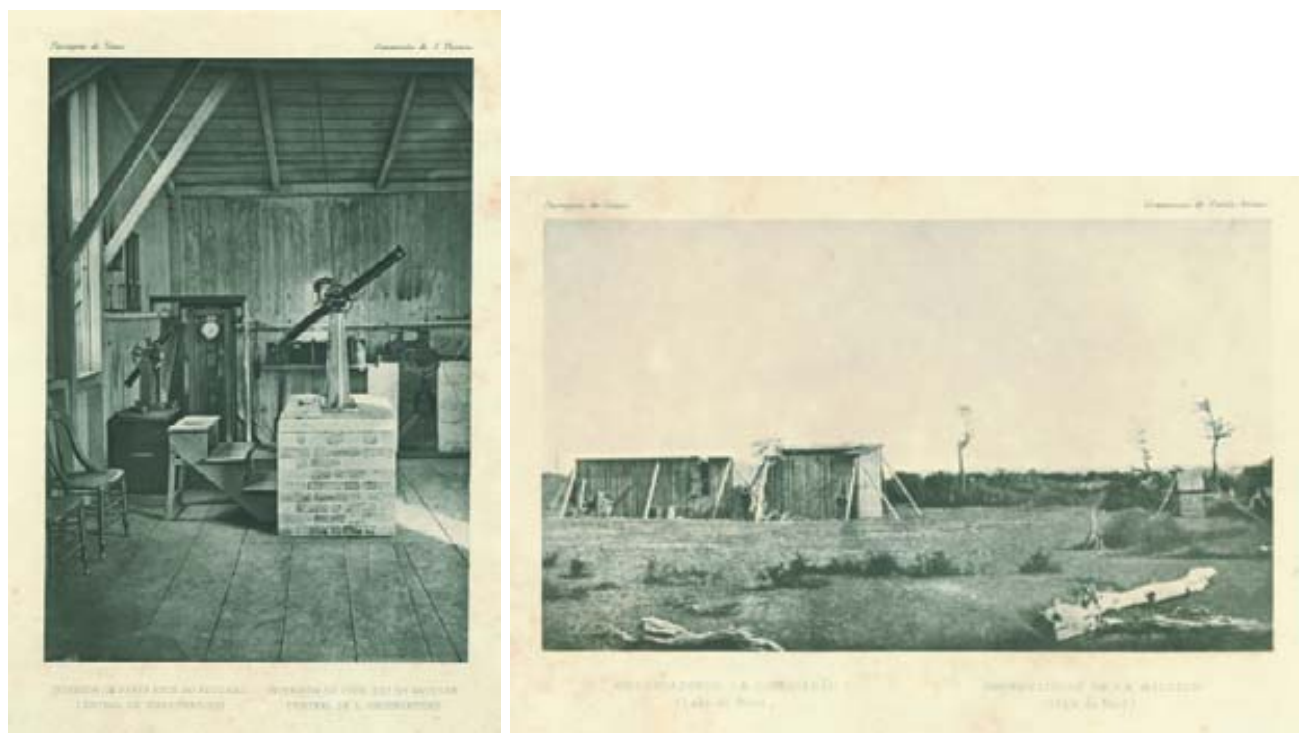

Figure 3. (Left panel) The Commission of St Thomas, West Indies: interior of the east part of the central pavilion of the Brazilian Observatory. In this place the passage of the planets was observed by the meridian. From that observation rigorous determination of the local time was made, a fundamental factor to accurately measure the contact of Venus entering the disk of the Sun. (Right panel) The Commission of Punta Arenas, Chile: The Brazilian astronomer of Belgian origin Luiz Cruls was the chief of the Brazilian mission to Punta Arenas. The clear visibility of the Chilean sky allowed the whole phenomenon to be registered.

Up to the establishment of Kepler's three laws that rule the movements of the planets, especially the third law, the absolute distances of the heaven bodies in the solar system were completely erroneous (although the relative distances were well-known from the time of Copernicus). According to these laws, there is an exact relationship between the squares of the planets' orbital periods and the cubes of the radii of their orbits. Indeed, this law constitutes a link of connection of all bodies of the solar system amongst themselves. In fact, when determining the distance of any planet to Earth it is possible to find the distance of another planet from the sun due to their revolution periods around the Sun. In the observation of planet Mars in 1672, that the French astronomer of Italian origin, Giovanni Cassini (1625-1712), determined the distance of the Sun to be 140 million km, multiplying by 20 times the distance of the Sun to the Earth, consequently determining all the other measures of the solar system.

Taking this advantage from English astronomer James Gregory's (1638-1675) idea, astronomer Edmund Halley (1656-1742) suggested the observation of the transit of Venus across the solar disk as a method to best calculate the solar parallax. The passages or transits of Venus occurred when Earth, Venus and Sun are aligned in relation to a located observer in the terrestrial surface. At this time, Venus is projected as a black disk on the brilliant larger disk of the Sun. Halley suggested that the solar disk could be used as a background reference, making it easier to determine the movement of Venus. Thus, no device for measuring angle would be needed, because Halley suggested that the instant of contact should be measured of the black disk of Venus with the limb of the Sun. The use of this method justified at the time the rudimentary devices for measuring angles.

\section{Transit of 1874}

In 1874 several expeditions were sent to China, Japan, India, Egypt, Russia, Gulf of Bengal, Sumatra, Java, St Paul Island, Saigon and Australia, by France, Germany, 


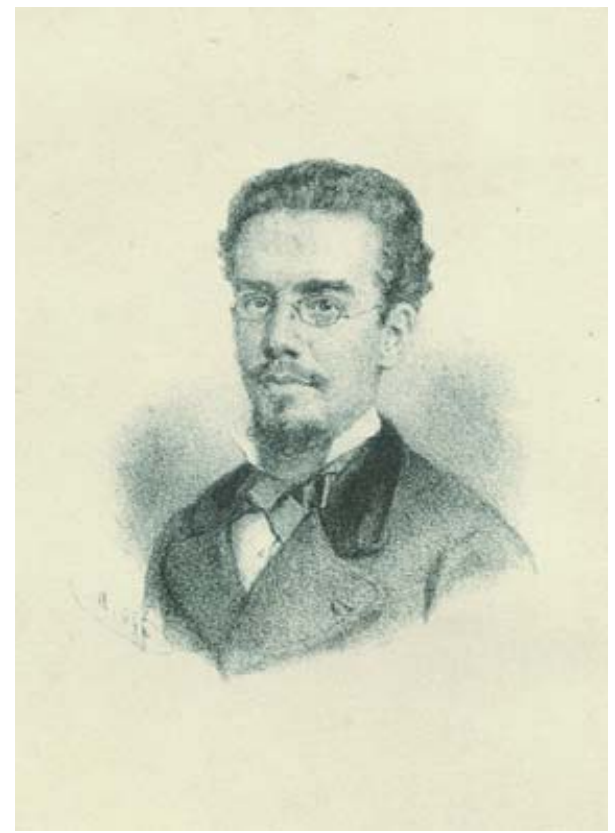

Figure 4. Francisco Antônio of d'Almeida, doctor of Physics and Mathematics who was sent by Conde Prados, director of the Imperial Observatory of Rio de Janeiro, to study astronomy in France. When participating in the French commission's transit of Venus in Nagasaki in 1874, Almeida was the responsible for the use of the photographic revolver created by the French astronomer Jules Janssen (1824-1907). This device is considered one of the precursors of the movies.

England and the USA to observe the phenomenon. In Nagasaki, as a member of the French mission, a young Brazilian astronomer, Francisco Antônio de Almeida (known in France as d'Almeida; Fig. 4), was responsible for the operation of the French astronomer Jules Janssen's (1824-1907) photographic revolver, a device considered as the precursor of cinema. The value found for the AU by several commissions was of $148900000 \pm$ $2000000 \mathrm{~km}$.

\section{Transit of 1882}

Immediately a campaign in the press and in the Parliament began against sending expeditions abroad. Whilst the Brazilian caricaturist, of Italian origin, Ângelo Agostini (1843-1910) made people laugh with his political cartoons against the Emperor and his idea of sending two missions abroad to observe Venus pass before the Sun. The senator Ferreira Viana (1834-1905), in the Parliament violently criticized the government's conjectures:

"Let's have this clear therefore, Minister of the Empire certainly that our astronomical missionaries will play the part of conductors of instruments for the wise men of France (laughs); on the other hand (the Parliament should admit the familiar sentence) they will make a big convescotte (laughs) in that we participated with the material part and French with the spiritual one, with the astronomical talents, with science, with the practical knowledge that they have acquired in similar observations and in the continuous study of the matter. Foreign missions. The mistake was reduced in half $(1000000 \mathrm{~km})$. Almost simultaneously, the determination began for the asteroids. The parallax of the Sun is an astronomical problem, that it is 


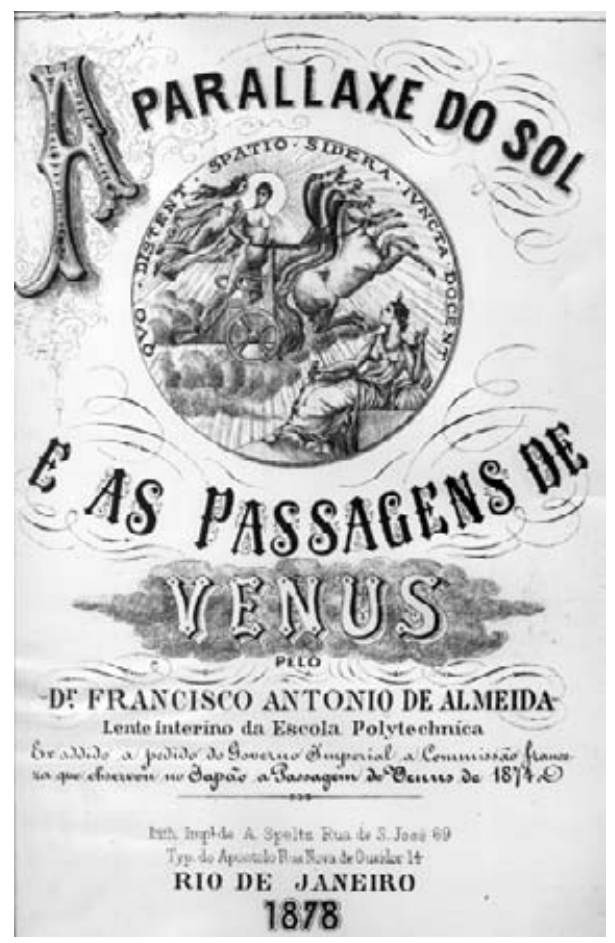

Figure 5. Frontispiece of the first book published in Brazil on the parallax of the Sun and the transit of Venus by the Brazilian astronomer Francisco Antônio of Almeida.

not vital; it doesn't have practical results to any human comfort or social interest, and it doesn't only depend upon the transit of Venus. Laplace already had made by the movement of the Moon; Priest Secchi refers to the process of speed [note of the author] of the light. There are more than ten or twelve processes to come to the foreseen result; and many authorities in the matter assured that none of them is evident and for sure. Consequently, it is a very problematic interest, even in the deep abstract root of science, however that we will put on an amount of money that has nothing of abstract, it is very positive (laughs)." (Annals of the Parliament, Section of March 22 of 1882, p.7).

Perhaps this was one of the most vivid debates ever to happen in Brazil about the use of basic science.

Actually, critics were justified in view of the determination of the solar parallax starting from the observation of the asteroids which had already begun to yield good and precise results compared to those obtained based in the observations of the passages of Venus. In fact, after having observed in 1874 on Mauritius Island, the Scottish astronomer Sir David Gill (1843-1914), disappointed with the method of the passage of Venus to determine the solar parallax, decided to use the planet Mars to settle the problem. For this purpose he decided to built an observatory on Ascension Island in the Atlantic ocean, where he accomplished a series of excellent photographic observations to measure the parallax of Mars in 1877 and, later, he used the same methods with recently discovered asteroids. As a result of those measures, the solar parallax was determined to be 8 ". 806 . For that reason Gill was not very enthusiastic to make any effort to observe the passage of Venus in 1882. In fact, in North America, in spite of the opposition of the president of the Congress (James Abram Garfield, 1831-1881 - later the president of the United States of America), a budget of about of US $\$ 175000$ was approved for the one mission 

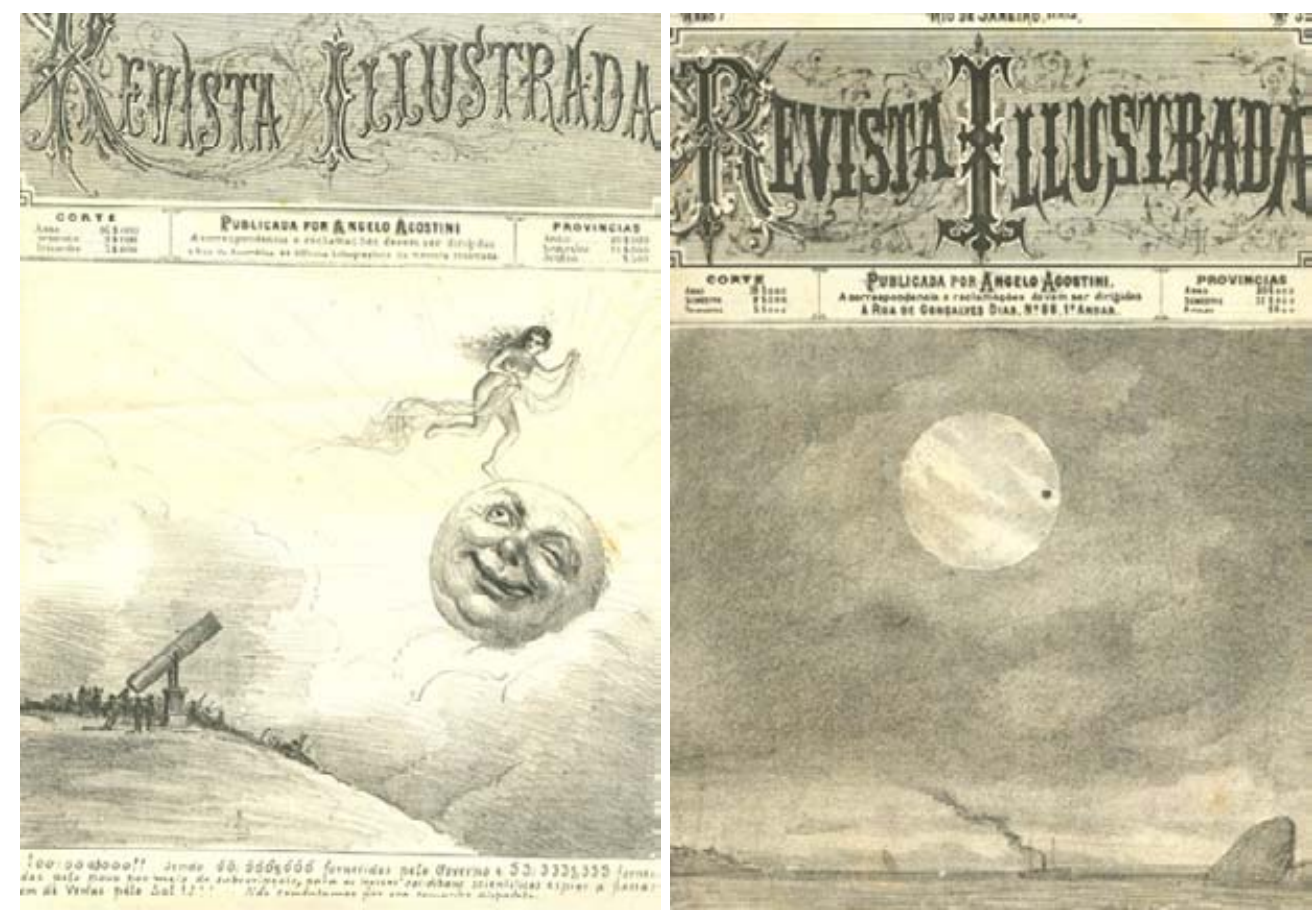

Figure 6. (Left panel) Frontispiece of Revista Ilustrada of 10 December 1880 by Ângelo Agostini (1843-1910) criticizing the budget expenditure directed to the observation of the transit of Venus by the solar disk. (Right panel) Frontispiece of Revista Ilustrada of 7 December 1882 by Ângelo Agostini (1843-1910) criticizing the difficulty in observing the transit in Rio de Janeiro, because of the foggy and rainy weather.

for the observation of the passage of Venus in 1874 in Nagasaki, in which the Canadian astronomer Simon Newcomb (1835-1909) participated. For the transit of 1882, the Congress of the USA approved a budget of US\$85000 without any political opposition, in spite of several astronomers' objection regarding the importance of the mission. Among them was Newcomb who had participated in the 1874 mission in Nagasaki. Once the resource was approved, he agreed to lead the mission to Wellington, South Africa, although he believed that the funds could have given better results with some other objectives. Several scientific bulletins with astronomy and natural history results were presented by Emperor Dom Pedro II to the Academy of Sciences at Paris for the Brazilian scientists.

The determination of the solar parallax by the Brazilian Commission, of 8!' 808 $(149400000 \pm 1000000 \mathrm{~km})$ represented at that time one of the most precise values. However, the error determined by Cruls is exactly the mentioned value in the speech made by Ferreira Viana. To have an idea, the accepted value in 1900 was of $8 .{ }^{\prime \prime} 806 \pm$ 0.'004 (149000 $000 \pm 100000 \mathrm{~km})$, based on Eros' parallax and calculated by the English astronomer Arthur Robert Hinks (1873-1945).

Until the appearance of radar astronomy, Eros' positional observation during its closest approach to Earth provided the best means to determine the solar parallax. With this purpose, thousands of measures were accomplished during the favourable 1900-01 appearance and 1930-31. The discussion of all of observations from 1893 to 1966 allowed astronomer J.H. Lieske to conclude that the solar parallax was of 8.'79402 \pm 0 "'00012. This is almost exactly the length of astronomical unit, $149600000 \mathrm{~km}$, adopted by the International Astronomical Union with base upon the measures of the radar astronomy of 


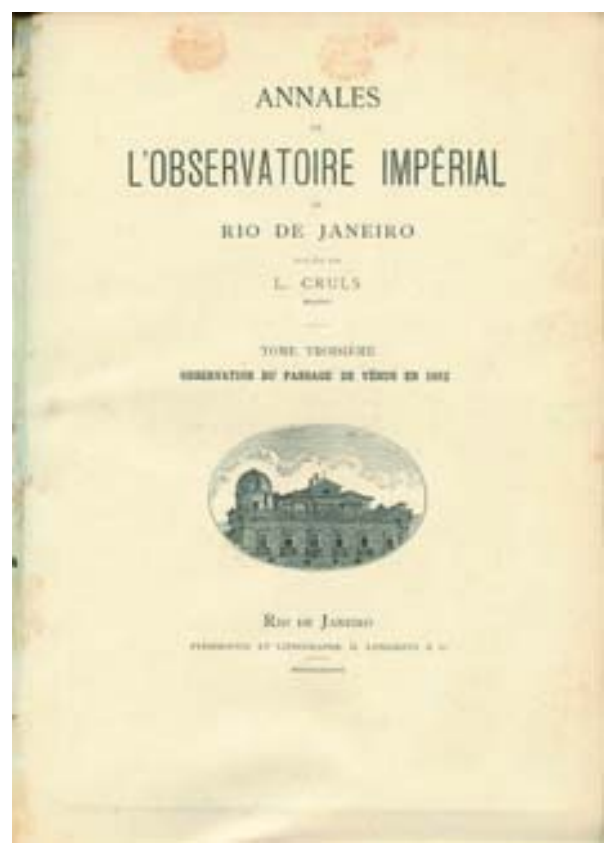

Figure 7. Frontispiece of the "Annals of the Imperial Observatory of Rio de Janeiro", published by Luiz Cruls, exclusively dedicated to the observation of the transit of Venus in 1882.

the planetary distances. In 1974, the International Astronomical Union adopted the solar parallax of 8.' $794148 \pm 0$.'00007 $(149598870 \pm 1000 \mathrm{~km})$, the average value determined by the USA, USSR and England through radar measurements at the beginning of the 1960s. In 1976 the International Astronomical Union adopted the value $149597870 \pm 2 \mathrm{~km}$, obtained based on the light travel time by unit of distance.

In the 19th century Brazil honoured the commitments assumed in Paris, in 1881, collaborating to determine this fundamental astronomical constant. It was a precious opportunity for Brazilian astronomy that never again participated in international efforts, since the observation of Eros in 1900-01 and 1930-31, to determine this measure with greater precision.

The creation of a Museum for the Passage of Venus, in Olinda, to commemorate the first participation of Brazil in a scientific enterprise of international repercussion is quite justified in view of the fact that a resolution of the International Astronomical Union decided that the sites where the passages of Venus were observed should be preserved, as well as documents and instruments used during the events. In Brazil, we have a good example of Sobral City Hall, in Ceará, that next to the commemorative monument of the site for the observation 1919 eclipses, confirming the theory of the relativity, a Museum of the Eclipse was built, providing a wide exhibition room and an enclosed observatory to the building of the Museum, with the objective to publicize the event and to register this important scientific effort. 